\title{
Nomegestrol Acetate or Chlormadinone Acetate Progestative Treatment in Women: Meningioma Behavior at Treatment Discontinuation
}

\author{
Simona Mihaela Florea ( $\nabla$ sm.floreamd@gmail.com ) \\ CHU Timone: Hopital de la Timone https://orcid.org/0000-0003-4152-2617 \\ Sebastien Boissonneau \\ CHU Timone: Hopital de la Timone \\ Thibault Passeri \\ Hôpital Lariboisière Service de Neurochirurgie: Hopital Lariboisiere Service de Neurochirurgie \\ Anne Laure Bernat \\ Lariboisière Hospital Neurosurgery Service: Hopital Lariboisiere Service de Neurochirurgie \\ Emmanuel Mandonnet \\ Lariboisière Hospital Neurosurgery Service: Hopital Lariboisiere Service de Neurochirurgie \\ Henry Dufour \\ CHU Timone: Hopital de la Timone \\ Thomas Graillon \\ CHU Timone: Hopital de la Timone \\ Sebastien Froelich \\ Lariboisière Hospital Neurosurgery Service: Hopital Lariboisiere Service de Neurochirurgie
}

\section{Research Article}

Keywords: meningioma, sex hormones, progestin, chlormadinone acetate, nomegestrol acetate

Posted Date: May 17th, 2021

DOI: https://doi.org/10.21203/rs.3.rs-517160/v1

License: (c) (i) This work is licensed under a Creative Commons Attribution 4.0 International License. Read Full License 


\section{Abstract}

Background: Associations between progestins and meningiomas is now well established. While the link between cyproterone acetate (CA) and meningioma was thoroughly studied, there is far less available data regarding the link between chlormadinone acetate (CHA) or nomegestrol acetate (NA) and risk of intracranial meningioma

Methods: We are presenting a series of 28 patients diagnosed with single or multiple meningiomas while treated with CHA-NA, in which the clinical and radiological course were analyzed after treatment discontinuation.

Results: 28 women, with a mean age of 56 years old, were diagnosed with one or multiple meningioma while being treated with either $\mathrm{CHA}$ or NA. After stopping treatment, $89.3 \%$ showed either tumor shrinkage or tumor stabilization on follow-up MRIs. Multiple meningiomas were more likely observed in patients with long periods of treatment (>10 years, $p$ 0.03) and seem to have a better clinical course ( $p$ 0.01). Most of the lesions were located on the skull base (55.4\%). Four patients with multiple meningiomas showed discordant tumors evolution, with some tumors growing while others were decreasing. Most of the growing meningiomas were either convexity or midline lesions and more posteriorly located.

Conclusion: Our study demonstrated a significant percentage of tumor diminution or stabilization after NA and CHA discontinuation. Therefore, treatment discontinuation with close monitoring should be the first measure taken if urgent surgery is not indicated. However, our results seem to be less encouraging than previously described in patients treated by CA, with more patients showing tumor growth despite treatment discontinuation. Further studies are needed to differentiate the effect of the different progestins treatment on meningiomas.

\section{Introduction}

Meningioma are the most frequent type of CNS tumors, representing over $30 \%$ of primary brain tumors in the population over 35 years of age, with a peak at 65 years [1]. The incidence of meningiomas is more than 2 times higher in the female population. Most meningiomas are benign, with over $80 \%$ grade I lesions according to the World Health Organization (WHO) classification and they originate in the arachnoid cells, that naturally express progesterone receptors[2]. Associations between hormones and meningiomas have been studied and are well established over time, with arguments such as: higher incidence in women, tumor growth during pregnancy and regression following child birth, an association between meningiomas and uterine fibroma, endometriosis or breast neoplasia, expression of PR and ER in meningiomas[3-7]. The expression of progesterone receptors in meningiomas has also led to the disappointing testing of antiprogesterone agents, such as mifepristone, that have shown a limited effect on unresectable meningiomas[8, 9].

A strong association between cyproterone acetate (CA), a progesterone derivate and meningioma was first reported in 2008 by Froelich et al[10], in a series of 9 patients with tumor regression after CA discontinuation. Since then, multiple similar reports have been published, and a clear relationship between meningioma and CA is now well established [11-15]. A recent study, based on the French national SNDS database, showed that women who initiated high dose CA treatment had a sevenfold increased risk of surgically treated meningioma with a strong dose-effect. It also confirmed the rapid regression of the risk after CA discontinuation. Since then, measures have been taken by the public health authority in France and in Europe[16-18]. These results concerning the relationship between meningiomas and CA led to an examination of the links between meningiomas and other treatments such as nomegestrol acetate or megestrol acetate[19, 20].

Chlormadinone acetate and nomegestrol acetate are synthetic progestins, prescribed for progesterone deficiency in premenopausal women (premenstrual syndrome, irregular menstrual cycle, mastodynia), functional uterine bleedings, menorrhagia due to uterine fibromas, endometriosis, dysmenorrhea and contraception (in association with an estrogen)[21, 22].

We have analyzed a series of 28 patients from two neurosurgical centers, presenting with meningioma, diagnosed in the context of treatment with either chlormadinone acetate (CHA) or nomegestrol acetate (NA).

\section{Patients And Methods}

Since an association between meningioma and progestins was reported, patients presenting with meningiomas in the neurosurgery departments of Lariboisière Hospital in Paris and La Timone Hospital in Marseille were questioned about the use of progestins.

The current study is a retrospective analysis of the clinical and radiological data of 28 patients (17 from Lariboisière Hospital, Paris and 11 from La Timone Hospital, Marseille) diagnosed with one or multiple meningiomas, while treated with either CHA or NA. Treatments were stopped at the time of diagnosis, and all patients were followed clinically and by serial MRIs, with an average of 4.2 months between the end of treatment and first follow-up radiological examination (range from 2 to 6 months). 
Patients presenting with severe symptoms at the time of diagnosis, requiring rapid surgery were not included in the study.

Tumor volume measurements were performed by two neurosurgeons on each MRI (MRI at the time diagnosis and the last MRI), using the Carestream ${ }^{\circledR}$ software, by manually contouring each meningioma on each slice. The contouring was then optimized with the 'repulsor' tool. Once the region of interest (ROI) was selected, the volume was automatically calculated with the segmentation function.

Volumetric assessment was based on the total tumor volume for each patient, by calculating the sum of the volumes of all lesions found in multiple meningiomas.

\section{Statistical methods}

Data management and analysis was performed with IMBs SPSS (SPSS Statistics 24) and the tests used to compare data were Fisher exact test or chi-square test and Fisher correlation coefficient. The p value considered as significant was $<0.05$.

\section{Results}

Our study includes 28 female patients, with a mean age of 56 years at the time of diagnosis (range: 37 to 74 ). 18 patients were treated with NA, 9 had CHA and one patient was treated by NA for 10 years and switched to CHA for another 9 years. The duration of hormonal treatment varied between 1 and 30 years (mean: 13.5 years). Patient's characteristics are summarized in Table 1. Multiple meningiomas (2 or more tumors) were seen in 13 patients, with a maximum of 12 meningiomas in one patient and a total of 65 meningiomas analyzed. Tumor location showed a predisposition for the skull base (36/65 were skull base tumors with only 2 meningiomas located on the posterior skull base), followed by the convexity (23/65) and midline (parasagittal or falx cerebri: 6/65). 
Table 1

Patient characteristics

\begin{tabular}{|c|c|c|c|c|c|c|c|c|c|c|}
\hline $\begin{array}{l}\text { Patient } \\
\text { no }\end{array}$ & Age & $\begin{array}{l}\text { Type of } \\
\text { hormone }\end{array}$ & $\begin{array}{l}\text { Duration } \\
\text { of } \\
\text { treatment } \\
\text { (years) }\end{array}$ & $\begin{array}{l}\text { Signes and } \\
\text { symptoms }\end{array}$ & $\begin{array}{l}\text { Number of } \\
\text { meningiomas }\end{array}$ & Localisation & $\begin{array}{l}\text { Clinical } \\
\text { outcome }\end{array}$ & $\begin{array}{l}\text { Initial } \\
\text { volume } \\
\text { (cc) }\end{array}$ & $\begin{array}{l}\text { Final } \\
\text { volume } \\
\text { (cc) }\end{array}$ & $\begin{array}{l}\text { Volume } \\
\text { evolution }\end{array}$ \\
\hline 1 & 45 & NA & 12 & Exophtalmia & 1 & ACF & I & 7.5 & 3.9 & $\mathrm{R}$ \\
\hline 2 & 49 & NA & 17 & AS & 2 & CONV $x 2$ & AS & 13.8 & 16.9 & G \\
\hline 3 & 60 & NA & 10 & $\begin{array}{l}\text { Palpebral } \\
\text { ptosis and } \\
5 \text { th nerve } \\
\text { neuralgia }\end{array}$ & 1 & MCF & I & 10.6 & 9.6 & $S$ \\
\hline 4 & 39 & $\begin{array}{l}\text { NA then } \\
\mathrm{CHA}\end{array}$ & $\begin{array}{l}10 \text { then } 9 \\
\text { (total } 19 \text { ) }\end{array}$ & AS & 2 & MCF, CONV & AS & 5.1 & 2.8 & $\mathrm{R}$ \\
\hline 5 & 45 & NA & 16 & Exophtalmia & 1 & MCF & I & 6.2 & 3.9 & $\mathrm{R}$ \\
\hline 6 & 67 & NA & 20 & $\begin{array}{l}\text { Visual } \\
\text { impairement }\end{array}$ & 3 & ACF x2 MCF & I & 11.6 & 6.2 & $\mathrm{R}$ \\
\hline 7 & 37 & NA & 10 & AS & 12 & $\begin{array}{l}\text { MCF x3 } \\
\text { CONV x6 } \\
\text { MID x3 }\end{array}$ & AS & 54.1 & 33.9 & $\mathrm{R}$ \\
\hline 8 & 56 & $\mathrm{CHA}$ & 8 & Epilepsy & 1 & CONV & AS & 2.2 & 2.4 & $S$ \\
\hline 9 & 59 & $\mathrm{CHA}$ & 18 & $\begin{array}{l}\text { Hard } \\
\text { subcutaneous } \\
\text { lump }\end{array}$ & 3 & $\begin{array}{l}\text { CONV ACF } \\
\text { PCF }\end{array}$ & $\begin{array}{l}\text { No } \\
\text { change }\end{array}$ & 61.2 & 53.3 & $\mathrm{R}$ \\
\hline 10 & 62 & $\mathrm{CHA}$ & 10 & AS & 2 & MCF CONV & AS & 8.1 & 6.8 & $\mathrm{R}$ \\
\hline 11 & 64 & NA & 30 & AS & 1 & ACF & AS & 11.1 & 9.6 & $\mathrm{R}$ \\
\hline 12 & 48 & NA & 8 & $\mathrm{H} / \mathrm{A}$ & 1 & MCF & AS & 1.7 & 0.6 & $\mathrm{R}$ \\
\hline 13 & 45 & $\mathrm{CHA}$ & 15 & AS & 6 & $\begin{array}{l}\text { MCF CONV } \\
\text { x4 MID }\end{array}$ & AS & 3.5 & 3.3 & $S$ \\
\hline 14 & 50 & NA & 9 & $\begin{array}{l}\text { Visual } \\
\text { impairement }\end{array}$ & 1 & MCF & I & 2.8 & 1.7 & $\mathrm{R}$ \\
\hline 15 & 71 & $\mathrm{CHA}$ & 10 & AS & 4 & $\begin{array}{l}\text { ACF MCF } \\
\text { CONV x2 }\end{array}$ & AS & 3.6 & 1.5 & $\mathrm{R}$ \\
\hline 16 & 64 & $\mathrm{CHA}$ & 16 & $\mathrm{H} / \mathrm{A}$ & 1 & CONV & $\begin{array}{l}\text { No } \\
\text { change }\end{array}$ & 7.9 & 8.1 & $S$ \\
\hline 17 & 49 & NA & 6 & AS & 1 & CONV & AS & 0.4 & 0.4 & $\mathrm{R}$ \\
\hline 18 & 70 & NA & 20 & AS & 2 & MCF MID & AS & 3.8 & 2.7 & $\mathrm{R}$ \\
\hline 19 & 71 & NA & 20 & AS & 1 & $\mathrm{ACF}$ & AS & 3.3 & 3.1 & $S$ \\
\hline 20 & 66 & NA & 1 & AS & 1 & MID & AS & 9.6 & 9.4 & $S$ \\
\hline 21 & 70 & $\mathrm{CHA}$ & 20 & AS & 3 & $\begin{array}{l}\text { ACF } \times 2 \\
\text { CONV }\end{array}$ & AS & 10.1 & 9.8 & $S$ \\
\hline 22 & 58 & $\mathrm{CHA}$ & 15 & $\begin{array}{l}\text { Visual } \\
\text { impairement }\end{array}$ & 1 & MCF & I & 2.2 & 2.3 & S \\
\hline 23 & 54 & NA & 7 & AS & 5 & $\begin{array}{l}\text { ACF } \times 2 \text { PCF } \\
\text { CONV } \times 2\end{array}$ & AS & 17 & 24.6 & G \\
\hline 24 & 38 & $\mathrm{CHA}$ & 5 & $\begin{array}{l}\text { Vth nerve } \\
\text { neuralgia }\end{array}$ & 1 & MCF & AS & 6.2 & 6.5 & S \\
\hline
\end{tabular}

AS - asymptomatic, H/A - headache, ACF - anterior cranial fossa, MCF - middle cranial fossa, PCF - posterior cranial fossa, CONV convexity, MID - midline, I -improvement, W - sworsening, R - regression, S - stable, G - growth NA - nomegestrol acetate, CHA chlormadinone acetate 


\begin{tabular}{|c|c|c|c|c|c|c|c|c|c|c|}
\hline $\begin{array}{l}\text { Patient } \\
\text { no }\end{array}$ & Age & $\begin{array}{l}\text { Type of } \\
\text { hormone }\end{array}$ & $\begin{array}{l}\text { Duration } \\
\text { of } \\
\text { treatment } \\
\text { (years) }\end{array}$ & $\begin{array}{l}\text { Signes and } \\
\text { symptoms }\end{array}$ & $\begin{array}{l}\text { Number of } \\
\text { meningiomas }\end{array}$ & Localisation & $\begin{array}{l}\text { Clinical } \\
\text { outcome }\end{array}$ & $\begin{array}{l}\text { Initial } \\
\text { volume } \\
\text { (cc) }\end{array}$ & $\begin{array}{l}\text { Final } \\
\text { volume } \\
\text { (cc) }\end{array}$ & $\begin{array}{l}\text { Volume } \\
\text { evolution }\end{array}$ \\
\hline 25 & 74 & NA & 20 & AS & 3 & ACF $\times 2$ MCF & AS & 3.1 & 3.5 & G \\
\hline 26 & 56 & NA & 8 & $\begin{array}{l}\text { Vth nerve } \\
\text { neuralgia }\end{array}$ & 1 & MCF & 1 & 0.7 & 0.3 & $\mathrm{R}$ \\
\hline 27 & 58 & NA & 20 & AS & 3 & $\begin{array}{l}\text { ACF } \times 2 \\
\text { CONV }\end{array}$ & AS & 57.1 & 51.4 & S \\
\hline 28 & 47 & NA & 9 & $\begin{array}{l}\text { Vth nerve } \\
\text { neuralgia }\end{array}$ & 1 & MCF & w & 11.9 & 12.5 & S \\
\hline
\end{tabular}

Mean duration of progestin treatment in patients with a meningiomatosis was 16 years versus 11.5 years for single meningiomas, indicating that multiple meningiomas are more likely to be found after prolonged use of CHA and NA ( $p$ value 0.03 ). 14 patients were symptomatic $(50 \%)$, most of them presenting with either visual symptoms (4 patients) or other cranial nerve deficit (4 patients). In the symptomatic group, 11 patients had a single meningioma, suggesting a better clinical course in case of multiple meningiomas ( $p$ value 0.01 ).

After progestin discontinuation, 1 patient among the symptomatic group worsened after 4 months and was operated, 2 remained stable while the other 11 patients (85\%) either improved or became asymptomatic. None of the asymptomatic patients at the time of diagnosis became symptomatic during the follow-up period.

The mean follow-up period was 29.4 months (6 to 114 months).

The histological analysis of the resected lesion showed a grade I meningothelial meningioma with a strong positive staining for progesterone receptor by immunochemistry.

An increase in total volume of $>10 \%$ was considered as tumor growth. A decrease in total volume of $>10 \%$ was considered as tumor regression. In between, the tumor volume was considered stable. In our series, total volume regression was documented in $50 \%$ of cases ( 14 patients), while 10.7\% (3 patients) had an increase in volume. 39.3\% (11 patients) were considered stable. No association between the number of meningioma or tumor location and tumor volume evolution was established. The evolution of the 65 meningiomas according to their localization is presented in Table 2. Picture 1 illustrates an example of radiological evolution on diagnostic and follow-up MRIs.

Table 2

Tumor localization and evolution on follow-up MRIs

\begin{tabular}{|c|c|c|c|c|c|c|c|c|c|}
\hline \multicolumn{2}{|c|}{ Tumor localization } & \multicolumn{2}{|c|}{$\begin{array}{l}\text { Regression } \\
\text { (n) (p) }\end{array}$} & \multicolumn{2}{|c|}{$\begin{array}{l}\text { Stable } \\
\text { (n) (p) }\end{array}$} & \multicolumn{2}{|c|}{$\begin{array}{l}\text { Growth } \\
\text { (n) (p) }\end{array}$} & \multicolumn{2}{|c|}{$\begin{array}{l}\text { Total } \\
\text { (n) (p) }\end{array}$} \\
\hline \multirow{3}{*}{$\begin{array}{l}\text { Skull base } \\
(23 / 65 ; 35.4 \%)\end{array}$} & ACF & 11 & $16.9 \%$ & 3 & $4.6 \%$ & 2 & $3.1 \%$ & 16 & $24.6 \%$ \\
\hline & MCF & 12 & $18.5 \%$ & 5 & $7.7 \%$ & 0 & $0 \%$ & 17 & $26.2 \%$ \\
\hline & PCF & 1 & $1.5 \%$ & 1 & $1.5 \%$ & 1 & $1.5 \%$ & 3 & $4.6 \%$ \\
\hline \multirow{3}{*}{$\begin{array}{l}\text { Non skull base } \\
(29 / 65 ; 64.6)\end{array}$} & CONV & 13 & $20 \%$ & 7 & $10.8 \%$ & 3 & $4.6 \%$ & 23 & $35.4 \%$ \\
\hline & MIDL & 4 & $6.1 \%$ & 0 & $0 \%$ & 2 & $3.1 \%$ & 6 & $9.2 \%$ \\
\hline & Total & 41 & $63 \%$ & 16 & $24.6 \%$ & 8 & $12.3 \%$ & 65 & 100 \\
\hline
\end{tabular}

In 4 patients with multiple lesions, we observed a discordant behavior with lesions increasing in size and other decreasing (Table 3 ). From a total of 16 meningiomas in those 4 patients, 6 showed tumor progression on the follow-up MRIs. 3/6 were located on the convexity; $2 / 6$ were on the anterior skull base and 4/6 were posteriorly located. Only 2 of the 12 anteriorly located lesions showed tumor progression during follow-up. 
Table 3

Discordant volume evolution in patients with multiple meningioma

\begin{tabular}{|c|c|c|c|c|c|c|c|c|c|}
\hline $\begin{array}{l}\text { Patient } \\
\text { no }\end{array}$ & Age & $\begin{array}{l}\text { Type of } \\
\text { hormone }\end{array}$ & $\begin{array}{l}\text { Signes and } \\
\text { symptoms }\end{array}$ & $\begin{array}{l}\text { No of } \\
\text { meningiomas }\end{array}$ & Localisation & $\begin{array}{l}\text { Clinical } \\
\text { evolution }\end{array}$ & $\begin{array}{l}\text { Initial } \\
\text { volume } \\
\text { (cc) }\end{array}$ & $\begin{array}{l}\text { Final } \\
\text { volume } \\
\text { (cc) }\end{array}$ & $\begin{array}{l}\text { Volume } \\
\text { evolution }\end{array}$ \\
\hline \multirow[t]{2}{*}{2} & 49 & NOMAC & $A / S$ & 2 & CONV ant & $\mathrm{A} / \mathrm{S}$ & 13.8 & 16.9 & G \\
\hline & & & & & CONV post & & & & \\
\hline \multirow[t]{3}{*}{13} & 45 & COMAC & $\mathrm{A} / \mathrm{S}$ & 6 & MCF & $\mathrm{A} / \mathrm{S}$ & 3.5 & 3.3 & ST \\
\hline & & & & & $\begin{array}{l}\text { CONV (ant } \\
\text { frontal) } \times 4\end{array}$ & & & & \\
\hline & & & & & MID (frontal) & & & & \\
\hline \multirow[t]{3}{*}{23} & 54 & NOMAC & $\mathrm{A} / \mathrm{S}$ & 5 & ACF $x 2$ & $\mathrm{~A} / \mathrm{S}$ & 17 & 24.6 & G \\
\hline & & & & & PCF & & & & \\
\hline & & & & & $\begin{array}{l}\text { CONV x2 } \\
\text { (post) }\end{array}$ & & & & \\
\hline \multirow[t]{3}{*}{25} & 74 & NOMAC & $\mathrm{A} / \mathrm{S}$ & 3 & $\begin{array}{l}\text { ACF (jugum } \\
\text { sph) }\end{array}$ & $\mathrm{A} / \mathrm{S}$ & 3.1 & 3.5 & G \\
\hline & & & & & ACF (ogm) & & & & \\
\hline & & & & & MCF & & & & \\
\hline
\end{tabular}

Overall, the percentage of tumor progression tends to be higher in the non-skull base tumor group compared to the skull base tumor group (respectively, $17.24 \%$ vs $8.3 \% ; p=0.027$ ), without reaching significance. No correlation was found between patient age and evolution of the lesions.

\section{Discussions}

The association between exogenous sex hormones and meningiomas has long been a subject of debate, with epidemiological studies showing an absence of link or a weak link between oral contraceptive pills (OC) or hormone replacement therapy (HRT) and the risk of meningiomas. While no studies clearly established an association between contraceptives and meningioma[23-26], several studies suggested a positive correlation between HRT and an increased risk of meningiomas[26-28]. In a large cohort study, Jhawar et al. reported that the risk of meningioma associated with current hormone use was 2.48 -fold for premenopausal women when compared with postmenopausal women who had never used HRT. The relative risk for postmenopausal women taking HRT was 1.86[28]. Conversely, two hospital-based case-control studies and one population-based case-control study found no association between HRT and meningioma[24, 29, 30]. A meta-analysis published in 2013 by Qi et al., concluded that HRT in postmenopausal women and an increased number of births were associated with an increased risk of meningioma, while oral contraception, age at menarche/menopause or age at first birth do not contribute significantly to the risk of developing meningiomas [26]. In a more recent meta-analysis, Benson et al. reported, that there is an increased risk of meningioma among HRT users with a relative risk of 1.35 (95\% confidence interval 1.21 to 1.49$)$ [27].

Since 2008, attention has focused more specifically on CA, following a report from Froelich et al. that showed evidence of tumor regression after treatment discontinuation[10]. Since then, multiple case reports and small series were published suggesting a positive association between CA and the risk of meningioma. Only recently, a larger study based on the French social security database published by Weill et al., proved the link between $\mathrm{CA}$ and meningioma, with a risk of having a meningioma treated with surgery or radiotherapy in women pursuing high doses of CA multiplied by 6.6. The study also confirmed a strong dose-effect and a noticeable reduction in risk after treatment discontinuation[15].

While the link between CA and meningioma was thoroughly studied, there is far less available data regarding the link between CHA-NA and risk of intracranial meningioma [20, 31-33]. The first suspicion of a link between NA and meningioma was published in 2004 by Cottin et al. who described the case of a patient diagnosed with a large meningioma after being treated with NA for 16 years for pulmonary lymphangioleiomyomatosis [34]. In 2008 Shimizu et al reported the case of an 80 years old male incidentally diagnosed with a meningioma on a CT scan following a head injury [33]. The patient was treated with CHA for a benign prostate hypertrophy. The authors noticed a significant volume reduction on follow-up imaging after his treatment was changed to an alpha-2-blocker. In 2019, Passeri et all described a 
series of 3 patients presenting with meningiomas and treated with NA, that showed spontaneous tumor regression after treatment discontinuation [20]. Champagne et al. also presented a case of a patient in which CHA and NA showed similar effect on meningiomas: growth under treatment and shrinkage after cessation of treatment[31]. In a recently published studying a consecutive series of patients between 1995 and 2008, Malaize et al. reported an increased number of patients diagnosed with progestin associated meningiomas over time. The rate of conservatively managed meningiomas also increased over time, with tumor regression seen in $29.6 \%$ of cases and tumor stability in $68.5 \%$ of patients [32].

In the present series, a clear favorable outcome of meningioma was observed after NA and CHA discontinuation, with most of the patients showing a regression in total tumor volume $(50 \%)$ or volume stabilization $(39.3 \%)$. By analyzing each of the 65 meningiomas, there was a higher percentage of tumor growth for midline and convexity lesions although these results were not statistically significant. Furthermore, $89 \%$ of our patients were asymptomatic at the end of the follow-up period with only one patient that worsened with a slight volumetric evolution on MRI.

Although there is a clear tendency towards regression or stabilization after NA and CHA discontinuation, similar to what is observed with CA, the percentage of tumor regression seems to be less important after cessation of CHA or NA [11, 15, 18, 32]. Bernat et al. reported a series of 12 CA-related patients, with tumor regression seen in over $90 \%$ of the patients. Malaize et al. showed that CA-related meningioma had a better answer to treatment discontinuation compared to $\mathrm{CHA}$ and NA-related tumors[11, 32].

Regarding tumor location, a predominance of anterior and middle skull base meningioma was observed, in accordance with previous findings $[15,18,36]$. Prolonged treatment (more than 10 years of progestin intake) seems to be linked to the occurrence of multiple meningioma and these patients appear to have a better clinical course than patients with single lesions. This is also in favor of the gradual appearance of new meningiomas under the influence of progestin intake. Discordant tumor evolution was seen in 4 patients with multiple meningiomas. Interestingly, in these patients, most of the growing meningiomas were either convexity or midline lesions, with a rather posterior location, while the majority of skull base and anterior convexity lesions showed significant regression.

A recent study by Peyre et al. that compared gene sequencing in progestin-associated meningioma vs a control group, showed a specific mutational landscape in progestins-related meningiomas, with a higher frequency of PIK3CA mutation (known to be associated with a more aggressive course in meningioma[37]) in hormone-related meningiomas[38]. When looking at NF2 and TRAF7 mutations (the 2 most frequent gene mutations in meningioma[37]), there was a significantly lower incidence of NF2 and a higher frequency of TRAF7 (40\% vs $26 \%$ ) when compared to the control group. Also, while TRAF7 were found to be associated with AKT1 and KLF4 mutations in the control group, in hormone-associated meningiomas there was a higher rate of isolated TRAF7 mutations.

Our results confirm the strong association between CHA-NA and meningioma. However, the results seem to be less encouraging than previously observed in patients treated by CA, with more patients showing tumor growth despite treatment discontinuation. Still, an important percentage of patients has a favorable response after treatment discontinuation. Therefore CHA-NA discontinuation and close observation should be, in our opinion, the first measure taken if urgent surgery is not needed. While the relationship between hormonal treatment and meningioma seems rather clear, the exact mechanisms of action are still to be determined. The long-term evolution after discontinuation of the drug is also unknown and requires larger scale studies to be properly determined.

\section{Conclusion}

Based on the present study, treatment with NA and CHA has a strong influence on meningiomas. However, the results seem to be less encouraging than previously observed in patients treated by CA. Still, the important rate of tumor regression or stabilization, as well as the good clinical outcome after cessation of treatment, is a strong argument for treatment discontinuation as the first measure in these patients. Although multiple meningiomas seem to be associated with a better outcome, close clinical and radiological follow-up is necessary, as discordant tumor courses might be seen. A thorough documentation of hormonal intake should be assessed in all meningioma patients, especially in women diagnosed with multiple meningiomas.

\section{Declarations}

Ethics approval: the study was approved by the local ethics committees from both institutions and validated by the national neurosurgical ethics committee (IRB00011687).

Funding: no funding was received to assist with the preparation of this manuscript.

Conflicts of interest: there are no conflict of interest in connection with this article. 
Availability of data and material: the datasets generated during and analyzed during the current study are available from the corresponding author on reasonable request.

\section{References}

1. Ostrom QT, Cioffi G, Gittleman H et al (2019) CBTRUS Statistical Report: Primary Brain and Other Central Nervous System Tumors Diagnosed in the United States in 2012-2016. Neuro-Oncology 21:v1-v100. https://doi.org/10.1093/neuonc/noz150

2. Verhagen KG, Go GM, Visser MA (1995) The presence of progesterone receptors in arachnoid granulations and in the lining of arachnoid cysts: its relevance to expression of progesterone receptors in meningiomas. Br J Neurosurg 9:47-50. https://doi.org/10.1080/02688699550041746

3. Claus EB, Calvocoressi L, Bondy ML et al (2013) Exogenous hormone use, reproductive factors, and risk of intracranial meningioma in females: Clinical article. JNS 118:649-656. https://doi.org/10.3171/2012.9.JNS12811

4. Omulecka A, Papierz W, Nawrocka-Kunecka A, Lewy-Trenda I Immunohistochemical expression of progesterone and estrogen receptors in meningiomas. Folia Neuropathologica 5

5. Pravdenkova S, Husain M (2006) Progesterone and estrogen receptors: opposing prognostic indicators in meningiomas. J Neurosurg 105:11

6. Wiemels J, Wrensch M, Claus EB (2010) Epidemiology and etiology of meningioma. J Neurooncol 99:307-314. https://doi.org/10.1007/s11060-010-0386-3

7. Kuroi Y, Matsumoto K, Shibuya M, Kasuya H (2018) Progesterone Receptor Is Responsible for Benign Biology of Skull Base Meningioma. World Neurosurgery 118:e918-e924. https://doi.org/10.1016/j.wneu.2018.07.100

8. Grunberg SM (1994) Role of antiprogestational therapy for meningiomas. Hum Reprod 9:202-207. https://doi.org/10.1093/humrep/9.suppl_1.202

9. Grunberg SM, Weiss MH, Spitz IM et al (1991) Treatment of unresectable meningiomas with the antiprogesterone agent mifepristone. J Neurosurg 74:861-866. https://doi.org/10.3171/jns.1991.74.6.0861

10. Froelich S, Bernat AL, Cebula H (2008) Does cyproterone acetate promote multiple meningioma? Berlin

11. Bernat AL, Oyama K, Hamdi S et al (2015) Growth stabilization and regression of meningiomas after discontinuation of cyproterone acetate: a case series of 12 patients. Acta Neurochir 157:1741-1746. https://doi.org/10.1007/s00701-015-2532-3

12. Bernat A, Bonnin S, Labidi M et al (2018) Regression of giant olfactory groove meningioma and complete visual acuity recovery after discontinuation of cyproterone acetate. J Ophthalmic Vis Res 13:355. https://doi.org/10.4103/jovr.jovr_21_17

13. Cebula H, Kurbanov A, Zimmer LA et al (2014) Endoscopic, Endonasal Variability in the Anatomy of the Internal Carotid Artery. World Neurosurg 82:759-764. http://dx.doi.org/10.1016/j.wneu.2014.09.021

14. Gil M, Oliva B, Timoner J et al (2011) Risk of meningioma among users of high doses of cyproterone acetate as compared with the general population: evidence from a population-based cohort study: Risk of meningioma among users of high doses of cyproterone acetate. Br J Clin Pharmacol 72:965-968. https://doi.org/10.1111/j.1365-2125.2011.04031.x

15. Weill A, Nguyen P, Labidi M et al (2021) Use of high dose cyproterone acetate and risk of intracranial meningioma in women: cohort study. BMJ n37. https://doi.org/10.1136/bmj.n37

16. Agence nationale de sécurité du médicament et, des produits de santé (ANSM) (2020) Restrictions d'utilisation de l'acetate de cyproterone liees au risque de meningiome

17. European Medicines Agency (2020) Restrictions in use of cyproterone due to meningioma risk. 3

18. Champeaux-Depond C, Weller J, Froelich S, Sartor A (2021) Cyproterone acetate and meningioma: a nationwide-wide population based study. J Neurooncol 151:331-338. https://doi.org/10.1007/s11060-020-03672-9

19. Gruber T, Fenstermaker RA (2004) Multiple meningiomas arising during long-term therapy with the progesterone agonist megestrol acetate. J Neurosurg 100:4

20. Passeri T, Champagne P-O, Bernat A-L et al (2019) Spontaneous regression of meningiomas after interruption of nomegestrol acetate: a series of three patients. Acta Neurochir 161:761-765. https://doi.org/10.1007/s00701-019-03848-x

21. Druckmann R (2009) Profile of the progesterone derivative chlormadinone acetate - Pharmocodynamic properties and therapeutic applications. Contraception 79:272-281. https://doi.org/10.1016/j.contraception.2008.10.017

22. Lello S (2010) Nomegestrol Acetate: Pharmacology, Safety Profile and Therapeutic Efficacy. Drugs 70:541-559. https://doi.org/10.2165/11532130-000000000-00000 
23. Benson VS, Pirie K, Green J et al (2008) Lifestyle factors and primary glioma and meningioma tumours in the Million Women Study cohort. Br J Cancer 99:185-190. https://doi.org/10.1038/sj.bjc.6604445

24. Lee E, Grutsch J, Persky V et al (2006) Association of meningioma with reproductive factors. Int J Cancer 119:1152-1157. https://doi.org/10.1002/ijc.21950

25. Wigertz A, Lonn S, Hall P et al (2008) Reproductive Factors and Risk of Meningioma and Glioma. Cancer Epidemiology Biomarkers Prevention 17:2663-2670. https://doi.org/10.1158/1055-9965.EPI-08-0406

26. Qi Z-Y, Shao C, Huang Y-L et al (2013) Reproductive and Exogenous Hormone Factors in Relation to Risk of Meningioma in Women: A Meta-Analysis. PLoS ONE 8:e83261. https://doi.org/10.1371/journal.pone.0083261

27. Benson VS, Kirichek O, Beral V, Green J (2015) Menopausal hormone therapy and central nervous system tumor risk: Large UK prospective study and meta-analysis: Menopausal Hormone Therapy and Central Nervous System Tumor Risk. Int J Cancer 136:23692377. https://doi.org/10.1002/ijc.29274

28. Jhawar BS, Fuchs CS, Colditz GA, Stampfer MJ (2003) Sex steroid hormone exposures and risk for meningioma. J Neurosurg 99:848853. https://doi.org/10.3171/jns.2003.99.5.0848

29. Custer BS, Koepsell TD, Mueller BA (2002) The association between breast carcinoma and meningioma in women. Cancer $94: 1626-$ 1635. https://doi.org/10.1002/cncr.10410

30. Hatch EE, Linet MS, Zhang J et al (2005) Reproductive and hormonal factors and risk of brain tumors in adult females. Int J Cancer 114:797-805. https://doi.org/10.1002/ijc.20776

31. Champagne P-O, Passeri T, Froelich S (2019) Combined hormonal influence of cyproterone acetate and nomegestrol acetate on meningioma: a case report. Acta Neurochir 161:589-592. https://doi.org/10.1007/s00701-018-03782-4

32. Malaize H, Samoyeau T, Zanello M et al (2021) Evolution of the neurosurgical management of progestin-associated meningiomas: a 23year single-center experience. J Neurooncol. https://doi.org/10.1007/s11060-021-03696-9

33. Shimizu J, Matsumoto M, Yamazaki E, Yasue M (2008) Spontaneous Regression of an Asymptomatic Meningioma Associated With Discontinuation of Progesterone Agonist Administration. Neurol Med Chir(Tokyo) 48:227-230. https://doi.org/10.2176/nmc.48.227

34. Cottin V (2004) Should patients with lymphangioleiomyomatosis undergo screening for meningioma? Eur Respir J 24:888-889. https://doi.org/10.1183/09031936.04.10079704

35. Piper JG, Follett KA, Fantin A (1994) Sphenoid Wing Meningioma Progression after Placement of a Subcutaneous Progesterone Agonist Contraceptive Implant. Neurosurgery 34:723-725. https://doi.org/10.1227/00006123-199404000-00022

36. Maiuri F, Mariniello G, Guadagno E et al (2019) WHO grade, proliferation index, and progesterone receptor expression are different according to the location of meningioma. Acta Neurochir 161:2553-2561. https://doi.org/10.1007/s00701-019-04084-z

37. Clark VE, Harmancı AS, Bai H et al (2016) Recurrent somatic mutations in POLR2A define a distinct subset of meningiomas. Nat Genet 48:1253-1259. https://doi.org/10.1038/ng.3651

38. Peyre M, Gaillard S, de Marcellus C et al (2018) Progestin-associated shift of meningioma mutational landscape. Ann Oncol 29:681686. https://doi.org/10.1093/annonc/mdx763

\section{Figures}
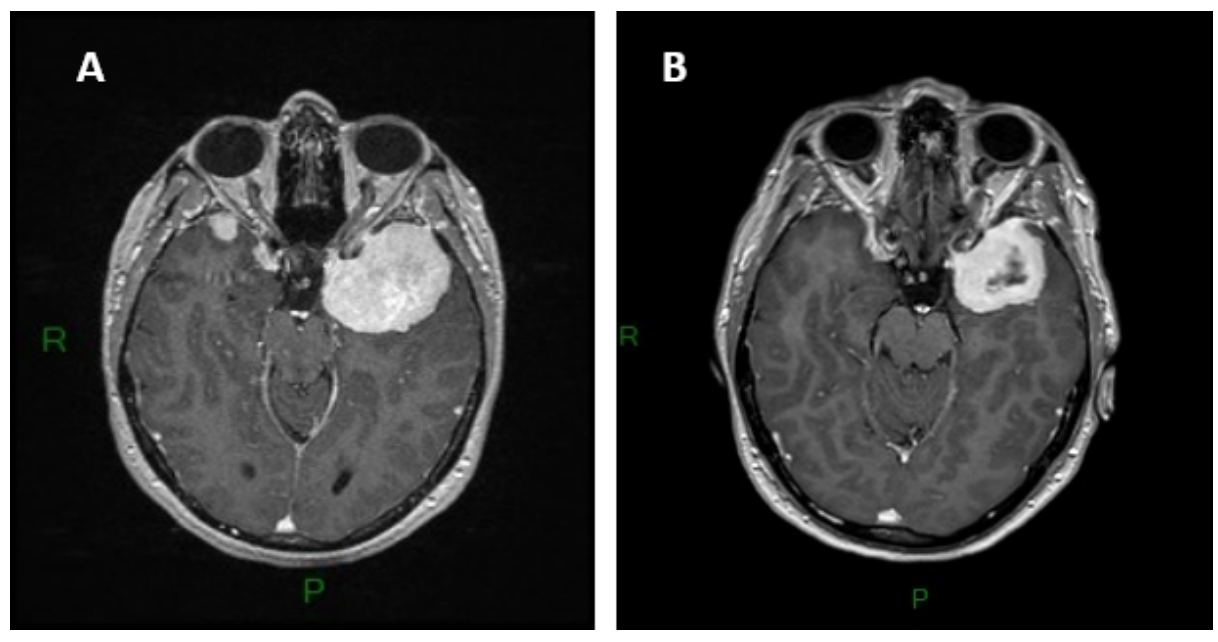

Figure 1

Page $9 / 10$ 
Example of meningioma evolution after CHA-NA discontinuation - Picture A shows a T1 gadolinium sequence of the initial MRI in a $37 y 0$ asymptomatic patient, on a screening MRI after 10 years of continuous NA intake; picture B illustrates a significant shrinkage of the large left sphenoid wing meningioma, as well as for the sphenoidal and cavernous tumors on the right side, 29 months after treatment discontinuation. 